condition of the nucous nembrane is materially changed. The muscular fibres are invigorated, secretion is more effciently performed and the patient reaches his destination in a much better condition than when he began his journey.

Salt water has long enjoyed a popular reputation of conferring immunity against the effects of exposure to cold. Fishermen and boatmen along the coast as well as sailors in mid-ocean pursue their laborious avocations in dripping garments without fear of "taking cold." How much of this protection is due to the salt contained in the water and air, and how much to the natural resistant power of a hardy organism, I shall not attempt to determine. Whether fishermen off the coast are less liable to attacks of catarrh of the respiratory passages than men who follow the same calling in fresh water I am unable to say, yet the general belief of seafaring men, founded upon abundant experience, must contain an element of truth. At all events, signal amelioration often attends a journey by sea in the case of bronchial and pulmonary disease. In chronic bronchitis inflammatory action is lessened, expectoration and cough are diminished, respiration becomes more free and sleep more sound. Vesicular emphysema is relieved by the favourable impression made upon the attendant bronchitis, by the tonic effect upon the heart and the improvement in digestion. In many cases of spasmodic asthma the patient, while at sea, is spared his distressing paroxysms. Attacks of hay astbma may be escaped by a sea voyage. A strong illustration of the neurotic element in asthma is the fact that those sufferers whose home is in the interior are more apt to be benefited by sea air than those who dwell near the coast. A voyage is a sovereign remedy for insomnia. When this habit is strictly dependent upon nervous strain or obstinate indigestion it vanishes as the conditions which gave rise to it infprove. Many people of middle age, however, without any apparently decided failure of general health are not able to readily fall asleep. They may feel drowsy before preparing for bed, but the act of undressing arouses them and by the time their heads touch the pillow they are wide awake. This wakefulness continues for some hours, the patient rolls in his bed and adopts various devices in order to woo sleep, but in vain. The mind is singularly active when one wishes rest, unpleasant subjects of thonght arise like magic and in time the patient dreads retiring for the night. This very apprehension intensifies the difficulty and thus the case progresses, and fortunate is the man who resists a strong temptation to have recourse to narcotics. 'The sea exerts a wonderful power in this condition. The ocean atmosphere possesses decided hypnotic virtue and "Nature's sweet restorer, balmy sleep" closes the eyes of the thankful traveller. An ocean voyage mitigates or suspends the pain of neuralgia. Free from torment, a hearty appetite, an abundant consumption of food, quickened oxidation and sanguification re-establish the nutrition of nervous tissue. The affected cords restored to health cease to be sources of agony. A remarkable happy effect is often produced in hemicrania. I have known patients whose pangs were periodical and excruciating to experience entire freedom during the passage, to suffer from no relapse for months afterwards, and indeed in some instances the malady has never since returned. A very pleasing effect is often produced in melancholia. The settled gloom is gradually dispelled. The poor sufferer little by little awakens to an interest in life, ceases to meditate continually upon his woes, listens to cheerful conversation and no longer avoids his fellows. The hypochondriac, improved in physical health, forgets his morbid fears. The hysterical girl, impressed by the majesty of Nature, with nerve centres fortified by the miltifarious influences of her unaccustomed surroundings, is led to forget her own personality, and ceases, for a time at least, to be a source of trouble or annoyance to her relatives. A more lasting effect is produced upon neurasthenia. New and richer blood feeds brain and spinal cord, languor disappears, and the patient returns home with a new lease of life. ('horeic children are often vastly improved, or even cured, by a sen-voyage. Jerking and irregular movements gradually decrease, sleep becomes uninterrupted and normal, coördination at last results. Epilepsyalso is often benefited. The spasms are mitigated in severity and recur at longer intervals. Ocean trarel is of conspicuous advantage to the subjects of anremia and chlorosis. It is unnecessary to repeat what has been already said concerning the freshened activity of the blood-forming organs. Suffice it to say that the capricious and perrerted appetite becomes keen and normal, pallor and discolouration rapidly ranish, the lips and mucous membranes acquire a rosy hue, muscular strength augments, and, ir. brief, the patient is soon cured. A sea voyage may vers appropriately be recommended to one who has just recoverec from an attack of purpura, particularly of the hæmorrhagic variety. Local disease of the skin remotely connected witt chlorosis is benefited by removal of its cause. As regards the menstrual function, the usual primary effect of crossing the ocean is suppression for a few periods, but the ultimate influence is beneficial. Dysmenorrhcea is sometimes, ano ovarian neuralgia generally, relieved.

(To be concluded.)

\section{A NATIONAL DANGER : LEAD POISONING FROM SERVICE PIPES. ${ }^{1}$}

BY ALFRED SWANN, M.D.,

MEDICAL OFFICER OF HEALTH FOR BATIEY; SURGEON TO THE BATLET AND DISTRICT HOSPITAL.

THIR'sers years have now passed since I first drew atten. tion to the great danger of supplying water for drinking anc dietetic purposes through leaden service pipes. During tha; period a great deal has been said and written upon this subject, but as far as I can gather the really fearful danger existing from this cause has either been ignored or only partially recognised. The general opinion seems to have been that the results of drinking water very slightly contaminated by lead were rather inconvenient than dangerous, and my object in writing the present paper is to show that a serious national danger exists, and I do not think after perusing these lines anyone can doubt my deductions. Ocular demonstration is a very important thing in a case like the present and a very simple means is at everyone's disposal for ascertaining the presence of lead in water. A solution of one grain of bichromate of potash to the ounce of distilled water furnishes everybody with a test capable of discovering 1 part of lead in 500,000 parts of water and I would recommend every medical man residing in districts suspected of lead poisoning to make use of the foregoing. My method has been as follows : To one gallon of water free from lead I have added one grain of lead acetate; to fifteen drachms of this solution one drachm of the bichromate solution is added. This gives the precipitate obtained by one grain of acetate of lead to the gallon of water. The original acetate of lead solution I dilute by halves : thus, $1 \mathrm{gr}$., $\frac{1}{2} \mathrm{gr}$., $\frac{1}{4} \mathrm{gr}$, , $\frac{1}{8} \mathrm{gr}$., $\frac{1}{16} \mathrm{gr} ., \frac{1}{32} \mathrm{gr}$., $\frac{1}{64} \mathrm{gr}$., and to each I add the same quantity of the test solution. This gives a series of graduated colour tests which can be used for com. parison with any sample of water brought for analysis.

The last ten samples of water tested by me in the foregoing manner give the following results :-

\begin{tabular}{|c|c|c|c|c|c|c|c|}
\hline Case & 1. 1 & & jua & of a grain of & ead & ate & yallo \\
\hline$"$ & 2. & " & ", & $\frac{1}{4}$ & $"$ & $"$ & $"$ \\
\hline " & & " & " & $"$ & $"$ & $"$ & $"$ \\
\hline ", & 4. & ", & " & $"$ & " & $"$ & $"$ \\
\hline " & 5. & " & $"$ & 1 grain of & ", & $"$ & $"$ \\
\hline$"$ & $\begin{array}{l}6 . \\
7\end{array}$ & $"$ & $"$ & $\begin{array}{l}\frac{1}{1} \text { of a grain of } \\
1 \text { grain of }\end{array}$ & $"$ & $"$ & ", \\
\hline " & 8 & $"$ & $"$ & 1 arain of & $"$ & $"$ & $"$ \\
\hline " & 9. & 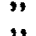 & $"$ & 1 grain of & $"$ & $"$ & \\
\hline 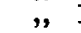 & 10. & $"$, & 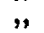 & $\frac{1}{2}$ a grain of & ", & $"$ & \\
\hline
\end{tabular}

The foregoing cases were taken haphazard in my daily practice between June 9 th and June 27th this year and represent a class of cases such as I have been treating without intermission for the past thirteen years.

CASE 1.-Female about sixty years of age, in easy circum. stances. Has suffered for many years and was told by a medical man some years ago that she had cancer of the stomach. Present condition : Never free from abdominal pain, which increases frequently to agonising colic; constipation; profound anæmia. Other members of the same household suffer from colic and digestive disturbances which disappear when they leave home.

CASE 2.-Female aged about thirty-four. Colic ; constipation ; anæmia ; frequent abortions.

CASE 3.-Male aged about forty. Colic; constipation; lumbago; rheumatic pains.

CAsE 4. - Female aged fifty-five. Progressive motor and sensory paralysis of legs; lumbar pain; constipation; colic occasionally.

1 For complete and exhaustive information on this subject I would refer to "Études sur les Eaux Potables et le Plomb," par A. Hamon Paris, 1884, to whom I am indebted for much valuable assistance. 
CASE 5. - Female aged twenty-five. Menstrual irregularities, sometimes profuse; constipation ; colic ; abortions.

CASE 6. - Female aged seventeen. Distressing colic ; constipation; menstrual irregularities; profound anæmia.

CASE 7.-Female aged thirty-eight. Profound anæmia; constipation ; colic ; menstrual irregularities.

CASE 8. - Male aged ten. Paroxysmal colic ; occasional diarrhœe ; choreic movements about eyes and hands ; anæmia.

CASE 9.--Female aged thirty-one. Constipation ; colic ; anæmia ; faintings ; confusion of ideas ; occasional loss of speech and sensation; mental condition gradually deteriorating. ${ }^{2}$

CASE 10.-Female aged fifty-eight. Anæmia ; constipation; lumbago; gout.

To the foregoing cases I would add the following :-

S. B-, aged about forty. Agonising colic ; blue line round teeth. Would not believe it was lead. A magnificent specimen of muscular humanity. For years went from bad to worse; dereloped albuminuria. Passed from under my care, but shortly after died of "apoplexy." Young son living in same house about ten years old. Completely paralysed (general paralysis); blue line round gums.

S. S_- aged thirty-five. Joiner. Suddenly went blind in right eye. Retinal hæmorrhage ; blue line round gums; constipation ; occasional colic.

I could multiply cases ad infinitum, but the foregoing are enough for my purpose. To justify the heading of this paper ${ }^{3}$ I must state that Mr. Walker of Heckmondwike, the inventor of the "health" iron tin-lined service pipe, has kindly allowed me access to his collection of sample specimens of water from the following districts. He has for some time adopted the following plan. After obtaining a sample of water from a given district he places in it a piece of polished lead and leaves it there. In the course of a very few days, sometimes hours, a precipitate begins to form and very soon the water becomes milky, and there really in many cases seems to be no limit to its solvent action under these conditions. He has informed me that he will be glad to show these specimens to anyone interested in the subject.

The following is a list of the waters of which Mr. Walker has specimens and which show a great power of dissolving lead, and I cannot do better than use his own words, which are as follows: "Distilled water acts very vigorously and throws down plenty of lead salts in a short time. Glasgow water acts still more vigorously and deposits more lead salts. Wakefield water acts very strongly on lead, making plenty of lead salts in a short time. Leeds water acts sometimes strongly and at other times very little. Morley water, which is from Leeds, we find acts strongly, but it also varies. Huddersfield, Mirfield, Dewsbury and Heckmondwike, Manchester, Oldham, Blackpool and Halifax act vigorously, all of them depositing lead salts, some acting rather more quickly than others. Batley, Eccleshill, Birstall, Gomersal, Pudsey, North Bierley act very vigorously. Barnsley, Clifton, Rastrick and Brighouse, all these have an affinity for lead, though not so strong as the others. Newcastle-on-'Tyne water takes the lead into solution, but does not throw down or deposit lead salts; but having had only one sample of this water I am not prepared to speak with certainty of it. Liskeard water acts very vigorously.'

This list is quite sufficient justification for the heading of this paper and the urgency of the subject is increased by the fact that at the present time local authorities seem to be making positively no efforts to check the use of leaden service piping. When we realise that half a century before the Christian era Vitruvius condemned lead service pipes and 130 years after that time Galen did the same thing, it is a puzzle to my mind to know how it is that the use of such a poisonous means of conveying water should ever have become general.

The amount of physical suffering, mental ${ }^{4}$ degeneration and reath brought about by lead poisoning, coupled with the fact that children begotten by poisoned parents are puny, rickety and ill developed, both mentally and physically, makes one feel that the Emperor ${ }^{5}$ of olden days who made the use of lead pipes a capital offence was gifted with a prescience and wisdom unknown in our enlightened age.

Batley.

- Since writing above this patient has had an attack of right hemiplegia and loss of speech.

See also monograph already alluded to by M. A. Hamon. 4 See work already quoted by M. A. Hamon.

5 Vide Empoisonnement par l'emploi des Tuyaux de Plomb pour Ia conduite des Eaux Potables et des Boissons Alimentaires, par Louis Waguer. Paris, 1887.

\section{PARALDEHYDE: HYPNOTIC AND DIURETIC.}

BY J. COCKBURN SYSON, M.B. GLAS. \&C.

HAVING frequently had occasion within the last six months to use paraldehyde as a hypnotic it may be of interest to record one or two observations made during the admini. stration of the drug. In a case of senile arterial degeneration with considerable mental depression, restlessness, marked insomnia and where there existed a double aortic murmur, with a mitral regurgitant and enlarged left ventricle, I was induced to try the drug after unsatisfactory results from sulphonal, urethane, chloral \&c. At first forty minims in peppermint water were given and this was followed by a state of comparative restfulness, though sleep was not induced. Two hours later, the pulse being unchanged, thirty minims more of the drug were administered and within half an hour the patient dropped quietly to sleep, which lasted, more or less, for four hours. It was described as being more refreshing than that produced by sulphonal and not accompanied by the same depression and uncomfortable sweating. The offensive odour of the drug however was objected to and this could be detected in the patient's breath during the next forty-eight hours. Two nights later the same doses were given, but these failing to produce the desired effect a third dose of fifty minims was allowed three hours after the second. After this third dose it was noticed that, though the patient was evidently asleep, there was considerable muscular twitching and shifting about in the bed. At short intervals he would sit up (his eyes being closed the while) and make incoherent remarks, but when told to go to sleep would lie down again and remain perfectly quiet during periods of ten or fifteen minutes. This lasted for three hours, after which there was still more or lest drowsiness, though the patient did not again go to sleep. The pulse was not in any way weakened, but during tho ensuing twenty-four hours there was marked muscular weakness and polyuria.

On the third night after the last administration paraldehydt was again given, beginning this time with a dose of sixty minims. In twenty minutes the patient felt drowsy and was asked to lie down and go to sleep. At the end of an hour, being still awake, sixty minims more of the drug were administered, but only short snatches of sleep followed ant there was, as on former occasions, considerable muscular twitching and rambling talk. On the day following it was again remarked that the patient voided an excessive quantity of urine. There was no diarrhœa and the appetite was not interfered with. The muscular weakness was again very marked and during nearly twelve hours there was more or less stupor and drowsiness. Having failed to induce a fair amount of sleep with drachm doses, and feeling disinclined to push the drug further, I was forced reluctantly to fall back upon morphia.

In about three weeks from the last administration of paraldehyde cardiac compensation began to fail and there was considerable dropsy about the ankles and half-way up the legs. Remembering the diuretic action exhibited by paraldehyde, I was induced to again have resort to the drug with the hope of getting rid of the dropsy. Ninety minims were given at 10 P.M. Within twenty minutes the patient was aleep, though his rest was disturbed by the muscular twitchings and restless movements already merr. tioned. At 12 midnight he had become quieter, but was not asleep. The pulse being satisfactory and not apparently affected by the hypnotic, another drachm was administered and further snatches of sleep were induced. Altogether, with two drachms and a half of the drug something like three hours' sleep were procured, and followed by severa hours of quiet and drowsiness. During the following day the weakness and unsteadiness of gait were very marked, the patient walking with difficulty and having to steady himself by catching on to objects in his room. But the most strikin result was the complete disappearance within twelve hours of the dropsy, which had persisted more or less for a week, and the accompanying presence of polyuria. On a subsequen occasion as much as 120 minims of the drug were given in one dose, followed in two hours by 90 minims, but the excitement and spasmodic muscular movements were so great as to make me think the cure worse than the disease, and so for the 